\title{
Headache, anosmia, ageusia and other neurological symptoms in COVID-19: a cross-sectional study
}

\author{
Pedro Augusto Sampaio Rocha-Filho ${ }^{1,2^{*}}$, Pedro Mota Albuquerque ${ }^{1}$, Larissa Clementino Leite Sá Carvalho², \\ Mylana Dandara Pereira Gama² and João Eudes Magalhães ${ }^{2}$
}

\begin{abstract}
Background: Neurological symptoms are frequent among patients with COVID-19. Little is known regarding the repercussions of neurological symptoms for patients and how these symptoms are related to one another.

Objectives: To determine whether there is an association between the neurological symptoms in patients with COVID-19, and to characterize the headache.

Method: This was a cross-sectional study. All hospital inpatients and health workers at the Hospital Universitario Oswaldo Cruz with a PCR-confirmed COVID-19 infection between March and June 2020 were considered for the study and were interviewed by telephone at least 2-months after the acute phase of the disease. These patients were identified by the hospital epidemiological surveillance department. A semi-structured questionnaire was used containing sociodemographic and clinical data and the ID-Migraine.

Results: A total of 288 patients was interviewed; $53.1 \%$ were male; with a median age of 49.9 (41.5-60.5) years; 91.7\% presented some neurological symptom; $22.2 \%$ reported some neurological symptom as the symptom that troubled them most during COVID-19. Neurological symptoms were: ageusia (69.8\%), headache (69.1\%), anosmia (67\%), myalgia (44.4\%), drowsiness (37.2\%), agitation (20.8\%); mental confusion (14.9\%), syncope (4.9\%) and epileptic seizures (2.8\%). Females, those who presented with fever, sore throat, anosmia/ageusia and myalgia also presented significantly more with headache (logistic regression). The most frequent headache phenotype was a non-migraine phenotype, was of severe intensity and differed from previous headaches. This persisted for more than 30 days in $18 \%$ and for more than 90 days in 10\% of patients. Thirteen percent of those with anosmia and $11 \%$ with ageusia continued with these complaints after more than 90 days of the acute phase of the disease. Aged over 50 years, agitation and epileptic seizures were significantly associated with mental confusion (logistic regression).
\end{abstract}

Conclusion: Headache is frequent in COVID-19, is associated with other symptoms such as fever, sore throat, anosmia, ageusia, and myalgia, and may persist beyond the acute phase of the disease.

Keywords: Neurologic manifestations, COVID-19, SARS-CoV-2, Headache, Anosmia, Ageusia

\footnotetext{
*Correspondence: pasrf1@hotmail.com; pedroasampaio@gmail.com

'Division of Neuropsychiatry, Centro de Ciências Médicas, Universidade Federal de Pernambuco (UFPE), Av. da Engenharia, 531-611, Recife, PE 50730-120, Brazil

${ }^{2}$ Hospital Universitario Oswaldo Cruz, Universidade de Pernambuco, Tv. Jackson Pollock - Santo Amaro, Recife, PE 52171-011, Brazil
}

(c) The Author(s). 2022 Open Access This article is licensed under a Creative Commons Attribution 4.0 International License, which permits use, sharing, adaptation, distribution and reproduction in any medium or format, as long as you give appropriate credit to the original author(s) and the source, provide a link to the Creative Commons licence, and indicate if changes were made. The images or other third party material in this article are included in the article's Creative Commons licence, unless indicated otherwise in a credit line to the material. If material is not included in the article's Creative Commons licence and your intended use is not permitted by statutory regulation or exceeds the permitted use, you will need to obtain permission directly from the copyright holder. To view a copy of this licence, visit http://creativecommons.org/licenses/by/4.0/ The Creative Commons Public Domain Dedication waiver (http://creativecommons.org/publicdomain/zero/1.0/) applies to the data made available in this article, unless otherwise stated in a credit line to the data. 


\section{Background}

During the COVID-19 pandemic, neurological symptoms and neurological diseases have been described, thereby reinforcing the possible involvement of both the central nervous system and the peripheral nervous system [1-5]. This involvement may occur during viral invasion, due to the systemic inflammatory process, hypoxia, vascular complications and postviral immunemediated complications [6].

Among the neurological diseases, there are reports of cerebrovascular diseases, encephalopathies, encephalitis, meningitis, myelitis, acute disseminated encephalomyelitis, Guillain-Barré syndrome, mononeuropathies and myopathies [1-5]. However, neurological diseases are more frequent in the most severe spectrum of the disease [7], and appear to be rare in terms of population. A population study in Singapore reported a $0.08 \%$ incidence of neurological diseases among those infected with SARS-CoV 2. This incidence does not include neurological symptoms, and anosmia and ageusia were not considered neurological diseases in this study [5].

On the other hand, neurological symptoms are much more common than neurological diseases and occur in 8 to $91 \%$ of hospitalized patients [2, 4, 810]. One study, conducted in two Spanish hospitals, reported that $2.5 \%$ of the 841 inpatients had sought hospital care due to neurological symptoms [9]. The most frequently reported neurological symptoms are headache, anosmia, ageusia, myalgia, mental confusion and an altered level of consciousness [1-4, 7-10]. These symptoms generally occur during the first days of COVID-19 symptoms [9-11] and headache, anosmia and ageusia are more likely to occur together [12-15]. In certain patients, some of these symptoms may persist beyond the acute phase of the disease [16]. Little is known regarding the repercussions of neurological symptoms for patients and how these symptoms are related to one another.

This study has aimed to determine whether there is an association between the neurological symptoms in patients with COVID-19, and also to characterize the headache presented by these patients.

\section{Method}

This was a cross-sectional study with a retrospective assessment conducted at the Hospital Universitario Oswaldo Cruz. This is a reference hospital for infectious diseases in the State of Pernambuco, Northeastern Brazil.

All adult inpatients and healthcare workers registered between March and June 2020 by the hospital's Epidemiological Surveillance Department as being suspected COVID-19 cases were identified, together with their telephone numbers. The inpatients had been referred from secondary hospitals that did not admit COVID-19 patients, and from emergency services in other hospitals.

All the patients aged over 18 years, diagnosed with COVID-19 confirmed by reverse transcription polymerase chain reaction (RT-PCR) technique, from material collected by nasal and oropharynx swab, were included in the study. No patient was diagnosed solely based on clinical symptoms. Patients who had any cognitive impairment that prevented the interview from being conducted, and those who died before the interview, were excluded.

Patients were tested by different kits of RT-PCR, according to the availability of the public health system at the time of the assessment: Molecular Kit SARS-Cov2(E/P1) (Bio-Manguinhos, Fiocruz, Rio de Janeiro, Brazil), BIOMOL Kit OneStep/COVID-19 (IBMP, Paraná, Brazil), AllplexTM 2019-nCov Assay (Seegene Inc., Minas Gerais, Brazil), and 2019-nCov CDC Assay (IDT Inc., Iowa, USA), respectively with a detection limit of $50,6,100$, and 8 copies per reaction. The tested specificity of all the kits was $>99 \%$.

\section{Data collection}

Patients were contacted by telephone at least 2-months after the acute phase of COVID-19, and were interviewed with regard to the symptoms presented during this phase. The onset of the acute phase was considered as the onset of the first symptom. Interviews were conducted from June to November 2020 by specifically trained resident neurology doctors and one medical student. Patients who presented with some degree of cognitive impairment or altered consciousness that prevented verbal communication were excluded.

Interviews were conducted using a semi-structured questionnaire. The first part of the questionnaire contained sociodemographic information, data regarding previously presented diseases (comorbidities) and a list of general symptoms and neurological symptoms, such as headache, myalgia ("Pain in the body (muscles)"), changes in the perception of smell ("Decreased smelling ability" and "I couldn't smell things") and of taste ("Decreased taste of food" and "I couldn't taste the food"), agitation ("Irritation/agitation"), a loss of consciousness ("fainting"), mental confusion, drowsiness ("Drowsiness (unable to stay awake)") and epileptic seizures. Each of these symptoms had dichotomous yes/no responses. Patients were also asked which symptom had troubled them the most during COVID-19.

The second part of the questionnaire was answered only by those who reported having headache, changes in smell and/or taste, plus details of the characteristics of these symptoms. 
To classify the phenotype of the headache presented during COVID-19, we used the Portuguese version of ID-Migraine. Those who obtained a score greater than or equal to 2 were considered as presenting "phenotypic migraine-like features" (a sensitivity of $92 \%$ and a positive predictive value of $93 \%$ for migraine diagnosis) [17].

In order to determine the time interval between the symptomatic phase of COVID-19 and the interview, the specimen collection date for the RT-PCR test and the date of the interview were used as a reference.

All patients provided an oral consent, and the research was approved by the National Research Ethics Commission in Brazil (CONEP; CAAE: 30479220.8.0000.5192; Report Number: 4.082.904).

\section{Availability of data and materials}

The data that support the findings of this study are available from the corresponding author upon reasonable request.

\section{Data analysis}

The statistical analyses were performed using SPSS 21.0 (IBM Corporation, Armonk, NY, USA).

Quantitative data were presented as medians and interquartile range (percentiles 25-75) since all distribution was non-normal according to the KolmogorovSmirnov test.

The percentage distribution of the categorical variables was compared between the groups by means of the Chisquare test or Fisher's exact test. Numerical variables were compared using the Mann-Whitney test.

Considering the existence of subsets of variables correlated with one another, which indicated aspects of the same dimension, we performed an exploratory factorial analysis with the principal component method and oblique rotation (direct oblimin). The Kaiser-Meyer-Olkin (KMO) measure and the Bartlett's test of sphericity indicated the adequacy of the model. Variables with factorial loadings over 0.4 were grouped according to their scores.

We also performed a logistic regression analysis to identify associations between the variables that presented the highest load among the encountered factors and the other sociodemographic and clinical factors. We previously defined using the pairwise deletion method in the analysis to address any missing data, but this proved to be unnecessary since we were able to collect data from all patients for the variables included in the regression models. We adjusted for possible confounders using these multivariate regression models. Variables were selected for the logistic regression models according to a $p$-value $<0.10$ in the univariate analysis. The stepwise method was used and we first included those variables with the highest values of the Qui-square test. Variables were maintained in the final model according to the stability of the model by comparing the standard error variation in order to avoid collinearity. Results are presented as bias-corrected odds ratios (OR) and 95\% confidence intervals $(\mathrm{CI})$ based on the analyses of 1000 computergenerated bootstrap samples.

Post-hoc analysis using the Bonferroni method was used to avoid the problem of multiple comparisons.

All tests were leveled by a 0.05 significance.

\section{Results}

During the assessed period, 964 patients were reported as being possible cases of COVID-19, of whom, 406 patients had a positive RT-PCR test for SARS-CoV 2 and were therefore eligible for the research. There were 112/406 losses (27.6\%) and six patients were excluded (Fig. 1).

Two hundred and eighty-eight patients were interviewed. The median time between the symptomatic phase and the interview was 111.5 (86-141.5) days. The median age was $49.9(41.5-60.5)$ years and $153 / 288$ (53.1\%) of the respondents were male.

Two hundred and twelve (73.6\%) patients reported some comorbidity: arterial hypertension $(121 / 288 ; 42 \%)$, overweight $(114 / 288 ; 39.6 \%)$, diabetes mellitus $(78 / 288$; $27.1 \%)$, asthma (29/288; 10.1\%); cardiac arrhythmia (17/ 288 ; $6 \%)$, kidney disease $(12 / 288 ; 4 \%)$, heart failure (10/ $288 ; 3.5 \%)$, myocardial infarction $(8 / 288 ; 2.8 \%)$, epilepsy $(8 / 288 ; 2.8 \%)$, liver disease $(3 / 288 ; 1 \%)$ and Parkinson's disease $(1 / 288 ; 0.4 \%)$.

Table 1 demonstrates the symptoms presented during COVID-19. The most frequent neurological symptoms were ageusia, headache, anosmia and myalgia.

One hundred and sixty patients reported some respiratory symptom, 91.7\% (264/288) reported some neurological symptom, and 64/288 (22.2\%) reported some neurological symptom as being the symptom that troubled them the most during COVID-19. Fifty-eight patients $(20.1 \%$; 58/288) reported some painful complaint as being that which troubled them the most during the disease. The complaint that troubled patients the most was headache for $27 / 288$ (9.4\%), ageusia for $10 / 288$ (3.5\%), anosmia for $9 / 288(3.1 \%)$ and myalgia for $8 / 288$ (2.8\%) of the interviewees.

Anosmia was the first symptom of COVID-19 in $56 / 193$ (29\%) and began at the same time as the other symptoms in 63/193 (32.6\%) of those who reported this complaint. Twenty-five people still reported anosmia at the time of the interview (more than three months after the acute phase of the disease), and of these, 20 reported that it was improving, and five stated that it remained unchanged. The median duration of anosmia among those who no longer 


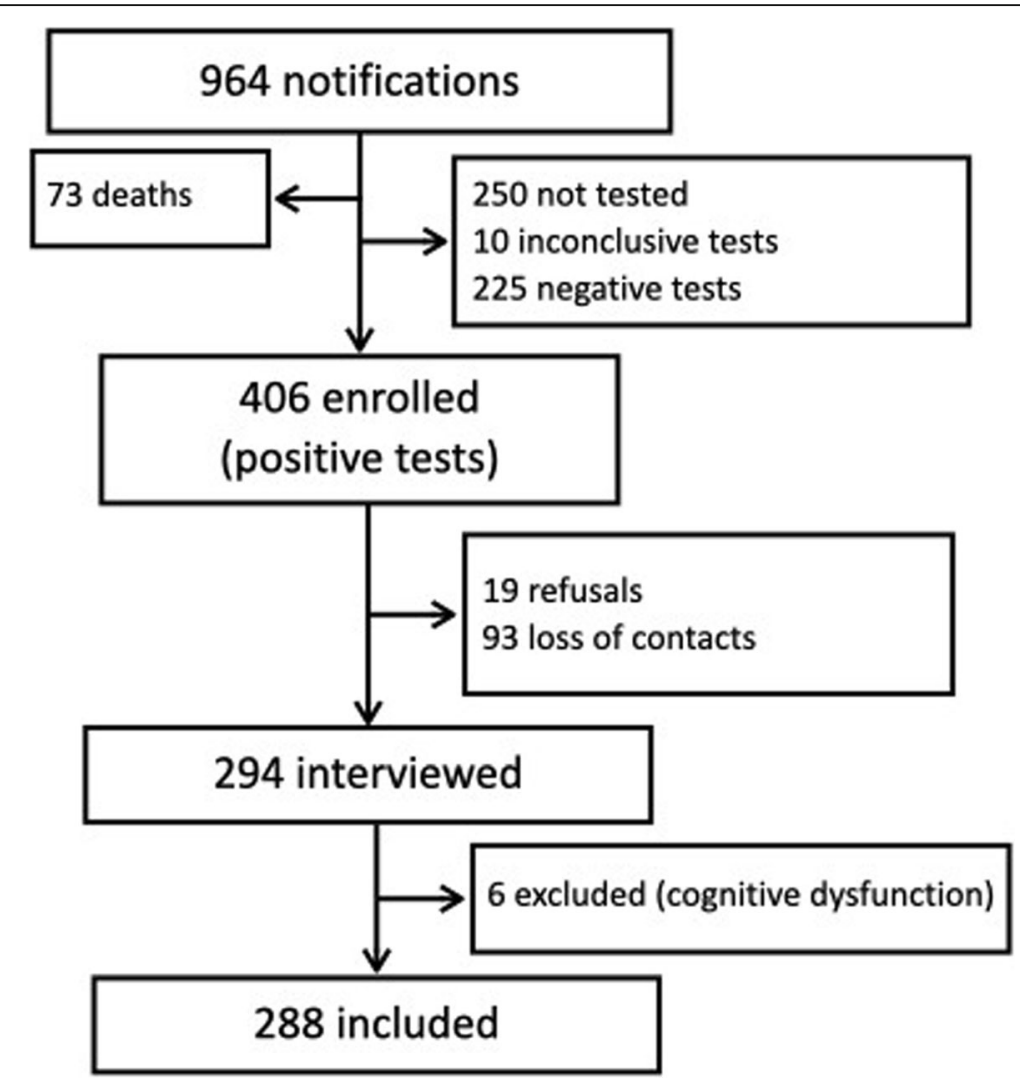

Fig. 1 Study flowchart

presented this symptom was 9 (7.5-15) days, and the maximum duration was 60 days.

Ageusia was the first symptom of COVID-19 in 55/ $201(27.4 \%)$ and began at the same time as the other symptoms in 74/201 (36.8\%) of those who presented this complaint. Twenty-two patients still reported having ageusia at the time of the interview (more than three months after the acute phase of the disease), and of these, 18 reported that it was improving and four patients stated that it remained unchanged. The median duration of ageusia among those who no longer had this symptom was 10 (7-16) days and the maximum duration was 60 days.

\section{Headache}

Headache was the first reported symptom in 84/199 (42.2\%) and began along with the other symptoms of COVID-19 in 75/199 (37.7\%).

Of the 199 patients who reported headache during the symptomatic phase of COVID-19, 27 (13.6\%) continued to present with this symptom. The median time between the symptomatic phase of these patients and the interview was 103 (79-170) days. Twenty patients reported that the headache was improving, although six stated that it remained unchanged. In 20/199 (10.1\%), the headache had lasted for more than three months.

The median duration of headache among the 172 who no longer had this symptom was 7 (4.5-12.5) days. In nine patients, the headache had lasted for a period of 30 to 60 days.

The median intensity of headache, using a scale from 1 to 10 , was 8 (5.5-9.5). Headache was associated with nausea in 85/199 (42.7\%), photophobia in 97/199 (48.7\%), limiting daily activities in 105/199 (52.8\%), and presented phenotypic migraine-like features (ID-Migraine greater than or equal to 2) in $98 / 199$ (49.3\%, $95 \%$ CI 42.1-56.4) of cases. Ninety-two patients (46.2\%; 92/ 199) who presented with headache reported having a previous headache and, of these, 78.3\% (72/92) assessed the COVID-19-associated headache as being different from any previous headaches.

No difference was recorded between those who did or did not have anosmia in the medians of intensity [8 (6-9) vs. $8(5-8)$ points, $p=0.232$ ] or duration [7 $(4.5-14.5)$ vs. $6(3.5-8)$ days; $p=0.071)$ of headache. There was also no association between having ageusia and the medians of the duration [7 (4.5-14) vs. 6 (3-10) days, $p=0.327$ ] or intensity [8 (6.5-9) vs. 7 (5.5-8), $p=0.374$ ] of headache. 
Table 1 Symptoms presented by patients with COVID-19

\begin{tabular}{lll}
\hline Symptoms & Total & \\
& $(\boldsymbol{n}=\mathbf{2 8 8})$ & $\mathrm{Cl} 95 \%$ \\
\hline Difficulty in breathing (Dyspnoea) & $223(77.4 \%)$ & $72.2-82.1$ \\
Fever & $199(69.1 \%)$ & $63.4-74.4$ \\
Cough & $196(68.1 \%)$ & $62.3-73.4$ \\
Fatigue & $196(68.1 \%)$ & $62.3-73.4$ \\
Drop in oxygen saturation & $165(57.3 \%)$ & $51.4-63.1$ \\
Chills & $119(41.3 \%)$ & $35.6-47.3$ \\
Diarrheia & $111(38.5 \%)$ & $32.9-44.4$ \\
Joint pains & $103(35.8 \%)$ & $30.2-41.6$ \\
Sore throat & $103(35.8 \%)$ & $30.2-41.6$ \\
Stuffy nose & $99(34.4 \%)$ & $28.9-40.2$ \\
Tight chest & $99(34.4 \%)$ & $28.9-40.2$ \\
Nausea & $94(32.6 \%)$ & $27.3-38.4$ \\
Abdominal pain & $70(24.3 \%)$ & $19.5-29.7$ \\
Vomiting & $67(23.3 \%)$ & $18.5-28.6$ \\
Cyanosis & $25(8.7 \%)$ & $5.7-12.6$ \\
NEUROLOGICAL SYMPTOMS & & \\
$\quad$ Any neurological symptom & $264(91.7 \%)$ & $87.9-94.6$ \\
$\quad$ Hypogeusia/ageusia & $201(69.8 \%)$ & $64.1-75$ \\
$\quad$ Headache & $199(69.1 \%)$ & $63.4-74.4$ \\
$\quad$ Hyposmia/anosmia & $193(67.0 \%)$ & $61.3-72.4$ \\
$\quad$ Myalgia & $128(44.4 \%)$ & $38.6-50.4$ \\
$\quad$ Drowsiness & $107(37.2 \%)$ & $31.6-43$ \\
$\quad$ Agitation & $60(20.8 \%)$ & $16.3-26$ \\
$\quad$ Mental confusion & $43(14.9 \%)$ & $11-19.6$ \\
$\quad$ Eyncope & $14(4.9 \%)$ & $2.7-8$ \\
\hline
\end{tabular}

\section{Association between symptoms}

All complaints were included in the factor analysis and those with a factor load above 0.4 were maintained. The KMO measure was 0.71 , indicating that the sample was adequate for a significance of less than 0.001 with the Bartlett's test of sphericity. The final model enabled the observation of two independent factors as indicated by the factor correlation of 0.16 (Fig. 2). The first factor included headache (highest load), sore throat, fatigue, myalgia, anosmia/ageusia, fever and chills. Taken together, they would seem to indicate the symptoms that predominate in the early stage of the disease. The second factor included mental confusion (highest load), aged over 50 years, comorbidity, cyanosis, agitation and dyspnea, which together, would seem to indicate a more severe stage of the disease.

Taking into account the symptoms with the highest factor load, two multivariate analyzes were performed. Table 2 presents the association between the sociodemographic and clinical characteristics with headache. After controlling for confounding variables, females, those presenting with fever, sore throat, anosmia/ageusia and myalgia remained significantly associated with headache.

Table 3 presents the association between the sociodemographic and clinical characteristics with mental confusion. After controlling for confounding variables, aged over 50 years, agitation and epileptic seizures remained significantly associated with mental confusion.

\section{Discussion}

We observed a high frequency of neurological symptoms in patients with COVID-19, which, among all the symptoms, were the complaints that most troubled $22 \%$ of patients. The most frequent neurological symptoms were ageusia, headache, anosmia and myalgia, which is in accordance with the literature [2-4, 7-9].

Our attention is drawn to the fact that the painful symptoms were extremely frequent and that they were among those that most troubled patients. In addition to headache and myalgia, joint pain, sore throat and abdominal pain were also frequently reported. Painful symptoms are rarely studied and little attention is paid to them by doctors in COVID-19, especially when faced with respiratory complaints, which have the greatest potential for causing complications. Our results reinforce the importance of actively researching pain and treating it appropriately.

We observed a high prevalence of headache, which was one of the symptoms that most troubled our interviewees, and thereby interfered with their daily activities. In another study, which only included patients who presented with headache, this was the symptom that most troubled $18.9 \%$ of patients [18]. In another study carried out in Spain that included both in-patients and outpatients, headache was the symptom that most bothered $15.6 \%$ of patients [19]. A recent systematic review found a prevalence of headache in the acute phase of COVID19 of $47.1 \%$ (95\%CI: $35.8-58.6 \%$ ) of patients, which is similar to our findings [20].

In our study, headache was more frequent in females and in patients with fever. While females have also presented a higher risk of headache in the acute phase of COVID-19 in other studies [8, 12, 21, 22], this was not the case in all studies [7, 13, 14, 23-26].

Fever is believed to be an important factor in the development of headache associated with systemic viral infections [18]. Despite this, only a very few studies have reported an association between headache and fever in the acute phase of COVID-19 [12, 22, 27] and most studies have not reported this association [14, 21, 23, 25]. Indeed, thus far, the possible association between headache and fever has not been the primary research question of any study. However, there is a biological 


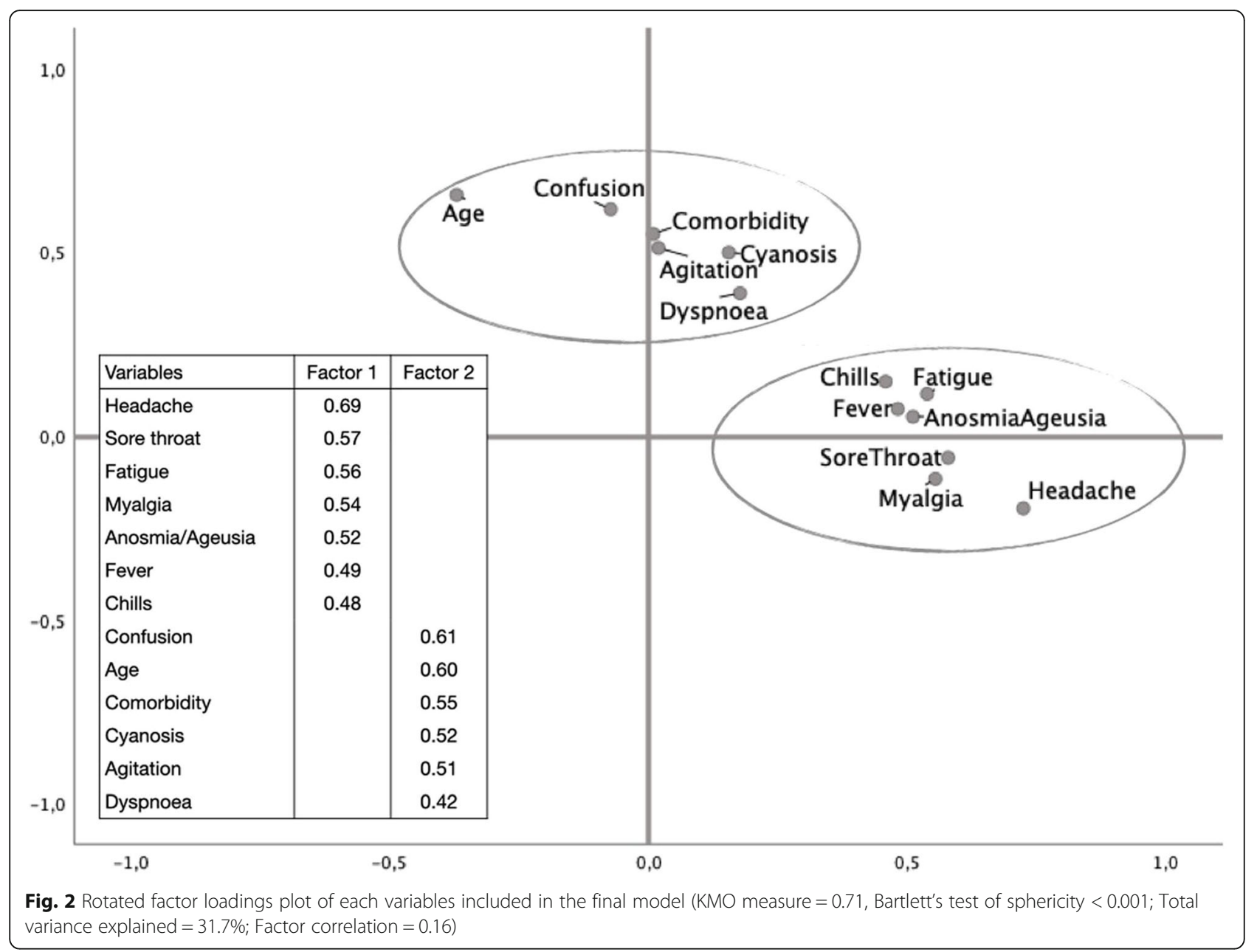

plausibility in an association between fever and headache in COVID-19. While some studies have reported an association between the occurrence of headache and proinflammatory substances such as NLRP3, HMGB1, and interleukin $6,[2,28]$ this has not been the case with all authors [21, 26, 29]. Moreover, a comparison between these studies is difficult because the levels of these substances were measured at different times.

When present, headache was generally the first to appear among all the COVID-19 symptoms, lasted for at least seven days, had a non-migraine phenotype, was of strong intensity and was different from previous headaches. The headache persisted for more than 30 days in $18 \%$ of those who reported headache and lasted for more than 3 months after the acute phase of COVID-19 in 10\%. Together, these data demonstrate that headache is not a minor problem, but a significant symptom of COVID-19.

The predominance of characteristics such as presenting early onset, $[12-14,18,24,25,30]$ of strong intensity, $[13,14,24,30]$ and being different from previous headaches [13, 14, 24, 25], have also been reported by other studies. The predominant phenotype of headache in COVID-19 (migraine or tension-type headache phenotype) is, however, controversial in the literature $[7$, $13,18,22,31$.

Our results corroborate with the few studies that have assessed the temporal behavior of headache and have reported that it may persist beyond the acute phase of the disease [7, 18-21, 23, 32, 33]. Persistent post-COVID-19 headache may be the result of multiple mechanisms such as direct neuro-invasion with damage along the neuronal pathway, the indirect effects of hypoxia, coagulopathy, and cytokine storm [34, 35]. Monitoring patients after the acute phase of the disease, even by telephone, may help to identify this headache so that it may be treated early, thereby reducing its impact.

We observed a high prevalence of anosmia and ageusia, which generally occurred at the onset of symptoms. The prevalence in our study is within the range described in the literature, although it is higher than most studies [36, 37]. The fact that patients were less severe $[7,37]$ and that data were obtained by direct patient interviews may have contributed to such a high prevalence. 
Table 2 Estimated risk for headache according to patient sociodemographic and clinical characteristics

\begin{tabular}{|c|c|c|c|c|c|c|}
\hline Characteristics & $\begin{array}{l}\text { Headache } \\
N=199\end{array}$ & $\begin{array}{l}\text { Without headache } \\
N=89\end{array}$ & $\begin{array}{l}\text { Total } \\
\mathrm{N}=\mathbf{2 8 8}\end{array}$ & $p$ value & Raw OR $(95 \% \mathrm{Cl})$ & Adjusted OR $(95 \% \mathrm{Cl})^{\mathrm{a}}$ \\
\hline Female sex, n (\%) & $111(55.8)$ & $24(27)$ & $135(49.9)$ & $<0.01$ & $3.42(1.98-5.90)$ & $3.13(1.64-5.97)$ \\
\hline Aged > 50 years, $n(\%)$ & $91(45.7)$ & $53(59.6)$ & $144(50)$ & 0.03 & $0.57(0.35-0.95)$ & $0.97(0.95-1.01)$ \\
\hline Comorbidity, n (\%) & $151(75.9)$ & $61(68.5)$ & $212(73.6)$ & 0.19 & $1.44(0.83-2.51)$ & - \\
\hline \multicolumn{7}{|l|}{ FLU SYMPTOMS: } \\
\hline Fever, n (\%) & $157(78.9)$ & $42(47.2)$ & $199(69.1)$ & $<0.01$ & $4.18(2.44-7.16)$ & $3.99(2.10-7.63)$ \\
\hline Chills, n(\%) & $95(47.7)$ & $24(27)$ & $119(41.3)$ & $<0.01$ & $2.47(1.44-2.47)$ & - \\
\hline Cough, n(\%) & $141(10.9)$ & $55(61.8)$ & $196(68.1)$ & 0.13 & $1.50(0.89-2.54)$ & - \\
\hline Sore throat, $n(\%)$ & $92(46.2)$ & $11(12.4)$ & $103(35.8)$ & $<0.01$ & $6.10(3.06-12.16)$ & $3.69(1.71-7.93)$ \\
\hline Dyspnoea, n (\%) & $159(79.9)$ & $64(71.9)$ & $223(77.4)$ & 0.13 & $1.55(0.87-2.77)$ & - \\
\hline Chest pain, n (\%) & $83(41.7)$ & $16(18)$ & $99(34.4)$ & $<0.01$ & $3.27(1.77-6.01)$ & - \\
\hline Low oxygenation, n (\%) & $111(55.8)$ & $54(60.7)$ & $165(57.3)$ & 0.44 & $0.82(0.49-1.36)$ & - \\
\hline Cyanosis, n (\%) & $20(10.1)$ & $5(5.6)$ & $25(8.7)$ & 0.22 & $1.88(0.68-5.17)$ & - \\
\hline Coryza, n (\%) & $80(40.2)$ & $19(21.3)$ & $99(34.4)$ & $<0.01$ & $2.48(1.39-4.43)$ & - \\
\hline Joint pain, n (\%) & $87(43.7)$ & $16(18)$ & $103(35.8)$ & $<0.01$ & $3.54(1.93-6.52)$ & - \\
\hline Diarrhea, n (\%) & $91(45.7)$ & $20(22.5)$ & $111(38.5)$ & $<0.01$ & $2.91(1.64-5.14)$ & - \\
\hline Nausea, n (\%) & $80(40.2)$ & $14(15.7)$ & $94(32.6)$ & $<0.01$ & $3.60(1.91-6.81)$ & - \\
\hline Vomiting, n (\%) & $56(28.1)$ & $11(12.4)$ & $67(23.3)$ & $<0.01$ & $2.78(1.38-5.61)$ & - \\
\hline Abdominal pain, n (\%) & $61(30.7)$ & $9(10.1)$ & $70(24.3)$ & $<0.01$ & $3.93(1.85-8.34)$ & - \\
\hline Flu, n (\%) & $198(99.5)$ & 78 (87.6) & $276(95.8)$ & $<0.01$ & - & - \\
\hline SARS, n (\%) & $199(100)$ & $83(93.3)$ & $282(97.9)$ & $<0.01$ & - & - \\
\hline \multicolumn{7}{|l|}{ NEUROLOGICAL SYMPTOMS: } \\
\hline Anosmia/Ageusia, n (\%) & $160(80.4)$ & $48(53.9)$ & $208(72.2)$ & $<0.01$ & $3.50(2.03-6.04)$ & $1.94(1.01-3.73)$ \\
\hline Myalgia, n (\%) & $107(53.8)$ & $21(23.6)$ & $28(44.4)$ & $<0.01$ & $3.77(2.15-6.61)$ & $2.40(1.26-4.59)$ \\
\hline Fatigue, n (\%) & $150(75.4)$ & $46(51.7)$ & $196(68.1)$ & $<0.01$ & $2.86(1.69-4.84)$ & $1.56(0.82-2.99)$ \\
\hline Somnolence, n (\%) & $80(40.2)$ & $27(30.3)$ & $107(37.2)$ & 0.11 & $1.54(0.91-2.63)$ & - \\
\hline Confusion, n (\%) & $26(13.1)$ & $17(19.1)$ & $43(14.9)$ & 0.18 & $0.64(0.33-1.24)$ & - \\
\hline Agitation, n (\%) & $41(20.6)$ & 19 (21.3) & $60(20.8)$ & 0.89 & $0.96(0.52-1.76)$ & - \\
\hline Syncope, n (\%) & $7(3,5)$ & $7(7.9)$ & $14(4.9)$ & 0.11 & $0.43(0.15-1.26)$ & - \\
\hline Seizure, n (\%) & $7(3,5)$ & $1(1.1)$ & $8(2.8)$ & 0.25 & $3.21(0.39-26.47)$ & - \\
\hline
\end{tabular}

Variables considered to the model: sex, age, fever, chills, sore throat, chest pain, coryza, joint pain, diarrhea, nausea, vomiting, abdominal pain, flu, SARS, anosmia/ ageusia, myalgia, fatigue

aFinal Model: myalgia, anosmia/ageusia, sex, sore throat, fever, fatigue, and age

By exploring the symptoms together, we encountered the presence of two groups of symptoms. The first includes headache, anosmia, ageusia and myalgia. The second includes mental confusion and agitation. Some flu-like symptoms were also grouped together with these neurological symptoms. As far as we are aware, this is the first study to demonstrate these two groupings in a theoretical model. Factor analysis, as a way of exploring a large set of symptoms, enabled us to observe an appropriate model for our sample, in which these groupings of symptoms seem to demonstrate common characteristics, in addition to appearing statistically reasonable to be able to assume their independence. These groupings of symptoms observed in our sample may be related to different stages of the disease, to common pathophysiological processes or to the severity of the patient [38-40].

In addition to being grouped in the factor analysis, headache was also associated with anosmia/ageusia and myalgia in the logistic regression model. Associations between ageusia and anosmia, $[23,41]$ between headache and myalgia, $[12,31]$ between headache and anosmia $[12,13,21]$ and between headache and ageusia [13, 21] have all been previously described. Headache, anosmia and ageusia usually occur at the beginning of the symptomatic period of COVID-19 [12, 13, 18, 25, 30, 42] and are more frequent in less severe cases [1, 7, 9, $12,21,25,31,37]$. The identification of micro-bleeds in 
Table 3 Estimated risk for mental confusion according to patient sociodemographic and clinical characteristics

\begin{tabular}{|c|c|c|c|c|c|c|}
\hline Characteristics & $\begin{array}{l}\text { Confusion } \\
N=43\end{array}$ & $\begin{array}{l}\text { Without confusion } \\
N=245\end{array}$ & $\begin{array}{l}\text { Total } \\
\mathrm{N}=\mathbf{2 8 8}\end{array}$ & $p$ value & Raw OR $(95 \% \mathrm{Cl})$ & Adjusted OR $(95 \% \mathrm{CI})^{\mathrm{a}}$ \\
\hline Female sex, n (\%) & $18(41.9)$ & $117(47.8)$ & $135(46.9)$ & 0.48 & $0.78(0.41-1.52)$ & - \\
\hline Aged $>50$ years, $n(\%)$ & $32(74.4)$ & $112(45.7)$ & $144(50)$ & $<0.01$ & $3.46(1.67-7.17)$ & $3.76(1.54-9.19)$ \\
\hline Comorbidity, n (\%) & $40(93)$ & $172(70.2)$ & $212(73.6)$ & $<0.01$ & $5.66(1.70-18.88)$ & $3.13(0.84-11.68)$ \\
\hline \multicolumn{7}{|l|}{ FLU SYMPTOMS: } \\
\hline Fever, n (\%) & $32(74.4)$ & $167(68.2)$ & $199(69.1)$ & 0.41 & $1.36(0.65-2.84)$ & - \\
\hline Chills, n(\%) & $21(48.8)$ & $98(40)$ & $119(41.3)$ & 0.28 & $1.43(0.75-2.74)$ & - \\
\hline Cough, n(\%) & $32(74.4)$ & $164(67)$ & $196(68.1)$ & 0.33 & $1.44(0.69-3.00)$ & - \\
\hline Sore throat, n(\%) & $17(39.5)$ & $86(35.1)$ & $103(35.8)$ & 0.58 & $1.21(0.62-2.35)$ & - \\
\hline Dyspnoea, n (\%) & $38(88.4)$ & $185(75.5)$ & $223(77.4)$ & 0.06 & $2.47(0.93-6.55)$ & - \\
\hline Chest pain, n (\%) & $18(42)$ & $88(33.1)$ & $99(34.4)$ & 0.26 & $1.46(0.75-2.83)$ & - \\
\hline Low oxygenation, n (\%) & $33(76.7)$ & $132(54)$ & $165(57.3)$ & $<0.01$ & $2.83(1.33-5.98)$ & $2.11(0.91-4.92)$ \\
\hline Cyanosis, n (\%) & $9(21)$ & $16(6.5)$ & $25(8.7)$ & $<0.01$ & $3.79(1.55-9.25)$ & $1.29(0.45-3.72)$ \\
\hline Coryza, n (\%) & $17(39.5)$ & $82(33.5)$ & $99(34.4)$ & 0.44 & $1.33(0.67-2.53)$ & - \\
\hline Joint pain, n (\%) & $21(48.8)$ & $82(33.5)$ & $103(35.8)$ & 0.05 & $1.90(0.99-3.65)$ & - \\
\hline Diarrhea, n (\%) & $16(37.2)$ & $95(38.8)$ & $111(38.5)$ & 0.85 & $0.94(0.48-1.83)$ & - \\
\hline Nausea, n (\%) & $14(32.6)$ & $80(32.7)$ & $94(32.6)$ & 0.99 & $0.99(0.50-1.99)$ & - \\
\hline Vomiting, n (\%) & $12(28)$ & $55(22.4)$ & $67(23.3)$ & 0.44 & $1.34(0.64-2.78)$ & - \\
\hline Abdominal pain, $\mathrm{n}(\%)$ & $19(44.2)$ & $51(21)$ & $70(24.3)$ & $<0.01$ & $3.01(1.53-5.92)$ & - \\
\hline Flu, n (\%) & $42(97.7)$ & $234(95.5)$ & $276(95.8)$ & 0.51 & - & - \\
\hline SARS, n (\%) & $43(100)$ & $239(97.6)$ & $282(98)$ & 0.30 & - & - \\
\hline \multicolumn{7}{|l|}{ NEUROLOGICAL SYMPTOMS: } \\
\hline Headache, n (\%) & $26(60.5)$ & $173(70.6)$ & $199(69.1)$ & 0.18 & $0.64(0.33-1.24)$ & - \\
\hline Anosmia/Ageusia, n (\%) & $33(76.7)$ & $175(71.4)$ & $208(72.2)$ & 0.47 & $1.32(0.62-2.82)$ & - \\
\hline Myalgia, n (\%) & $21(48.8)$ & $107(43.7)$ & $128(44.4)$ & 0.53 & $1.23(0.64-2.36)$ & - \\
\hline Fatigue, n (\%) & $32(74.4)$ & $164(67)$ & $196(68.1)$ & 0.33 & $1.44(0.69-3.00)$ & - \\
\hline Somnolence, n (\%) & $22(51.2)$ & $85(34.7)$ & $107(37.2)$ & 0.04 & $1.97(1.03-3.79)$ & $1.33(0.62-2.86)$ \\
\hline Agitation, n (\%) & $18(42)$ & $42(17.1)$ & $60(20.8)$ & $<0.01$ & $3.48(1.74-6.95)$ & $2.76(1.29-5.94)$ \\
\hline Syncope, n (\%) & $4(9.3)$ & $10(4.1)$ & $14(5)$ & 0.14 & $2.41(0.72-8.07)$ & - \\
\hline Seizure, n (\%) & $5(11.6)$ & $3(1.2)$ & $8(2.8)$ & $<0.01$ & $10.61(2.44-46.24)$ & $27.2(4.52-164.6)$ \\
\hline
\end{tabular}

Variables considered to the model: age, comorbidity, dyspnoea, low oxygenation, cyanosis, joint pain, abdominal pain, somnolence, agitation, Seizure

aFinal Model: seizure, agitation, age, comorbidity, cyanosis, low oxygenation, and somnolence

the olfactory bulb in patients with persistent headache and anosmia reinforces the hypothesis of a direct viral injury or vascular injury in the genesis of these two symptoms [43].

Mental confusion was associated with agitation and epileptic seizures. These symptoms occur more frequently in cases of greater severity, [1, 9, 44, 45] and therefore have a higher frequency in a hospital series [1, $10,44]$. The most severe phase of the disease generally occurs from the second week of the disease [39]. The systemic inflammatory process, hypoxia, and drug use may be significant factors for the occurrence of these symptoms, [38-40] which may also be associated with the development of an encephalopathic condition [40].
Our study has some limitations. The patients included were from a single center. This may limit the generalization of the study concerning milder cases. The epidemiological profile of health workers differs from those who presented to the emergency department and were hospitalized. Although the great majority of our patients were hospitalized, the patient list, provided by the hospital, does not indicate how many were inpatients and how many were health professionals who were treated as outpatients. Only patients who had been discharged and who were able to answer the questions were included in the study. This may have led to an underrepresentation of the more severe cases. The interview was 
conducted at least 2 months after the symptoms, which increases the chance of memory bias. The time interval between the acute phase of COVID-19 and the interview varied among patients. The semistructured questionnaire used was not validated and the quality, duration, and localization of the headache were not included in the questionnaire. The factorial analysis performed has an exploratory character and only enables interpretations within the studied sample and, although the obtained results present biological plausibility, they need to be corroborated by other studies. As a sample size calculation was not performed, we cannot rule out the possibility that small differences might not have been identified.

Losses accounted for $27.6 \%$. We cannot rule out the possibility that this may have interfered with the internal validity of the study. However, the frequency of neurological symptoms we observed is in agreement with that reported in the literature.

The most suitable study design to assess the duration of symptoms is the cohort study. Therefore, we must interpret this data carefully. However, since we know the dates on which the RT-PCR tests were performed (acute phase of the disease) and the interview dates, this data was used to estimate this duration.

A total of 250 patients had no RT-PCR results. The hospital protocol established that all inpatients or healthcare professionals who presented with symptoms suggestive of COVID-19 should be tested. However, as these patients were infected in the first wave of COVID19 in Brazil and our healthcare system was in disarray, not all of the collected tests were processed. These tests were not processed at our hospital. Thus, no form of selection process was adopted in order to choose which patients should perform the RT-PCR. We therefore decided that only patients with positive RT-PCR tests should remain in the study so as to reduce misclassification.

Our study has some strengths. In the period chosen for the selection of patients, those who had been admitted to the Hospital Universitario Oswaldo Cruz represented an expressive number of patients who needed hospitalization in the state of Pernambuco. Most of the interviews were conducted by trained doctors, experienced in addressing neurological symptoms. As the data were obtained by interview, the chance of information loss was decreased. Moreover, all patients included in the study had a positive RT-PCR test for SARS-CoV 2, thereby decreasing the chance of misclassification.

\section{Conclusion}

Neurological symptoms are frequent and significant in the acute phase of COVID-19. The most frequent neurological symptoms were ageusia, headache, anosmia and myalgia. Headache, anosmia and ageusia may persist beyond the acute phase of the disease. Headache was associated with females, fever, sore throat, ageusia/anosmia and myalgia. Mental confusion was associated with older age, agitation and epileptic seizures.

\section{Supplementary Information}

The online version contains supplementary material available at https://doi. org/10.1186/s10194-021-01367-8.

\section{Additional file 1}

\section{Acknowledgements}

The authors would like to thank Victor Torres Souza Lira and Djanino Fernandes Silva for helping in the data collection and to the Universidade Federal de Pernambuco (UFPE) for funding.

\section{Authors' contributions}

1) conception and design of the study (PASRF), 2) acquisition and analysis of data (PASRF, PMA, LCLSC, MDPG, JEM) 3) drafting a significant portion of the manuscript or figures (PASRF and JEM). All authors read and approved the final manuscript.

\section{Funding}

Universidade Federal de Pernambuco (UFPE); Grant Number: Edital Propesq 06/2020.

\section{Availability of data and materials}

The datasets used and/or analysed during the current study are available from the corresponding author upon reasonable request.

\section{Declarations}

Ethics approval and consent to participate

All patients provided their consent orally and the research was approved by the National Research Ethics Commission in Brazil (CONEP; CAAE:

30479220.8.0000.5192; Report Number: 4.082.904).

Consent for publication

Not applicable.

Competing interests

The authors declare that there is no conflict of interest.

Received: 27 September 2021 Accepted: 1 December 2021 Published online: 03 January 2022

\section{References}

1. Nersesjan V, Amiri M, Lebech AM, Roed C, Mens H, Russell L, Fonsmark L, Berntsen M, Sigurdsson ST, Carlsen J, Langkilde AR, Martens $P$, Lund EL, Hansen K, Jespersen B, Folke MN, Meden P, Hejl AM, Wamberg C, Benros ME, Kondziella D (2021) Central and peripheral nervous system complications of COVID-19: a prospective tertiary center cohort with 3month follow-up. J Neurol 268(9):3086-3104. https://doi.org/10.1007/s0041 5-020-10380-x

2. Karadaş Ö, Öztürk B, Sonkaya AR (2020) A prospective clinical study of detailed neurological manifestations in patients with COVID-19. Neurol Sci 41 (8):1991-1995. https://doi.org/10.1007/s10072-020-04547-7

3. Mao L, Jin H, Wang M, Hu Y, Chen S, He Q, Chang J, Hong C, Zhou Y, Wang D, Miao X, Li Y, Hu B (2020) Neurologic manifestations of hospitalized patients with coronavirus disease 2019 in Wuhan, China. JAMA Neurol e201127:2020.02.22.20026500 77(6):683-690. https://doi.org/10.1001/jama neurol.2020.1127

4. Liotta EM, Batra A, Clark JR, Shlobin NA, Hoffman SC, Orban ZS, Koralnik IJ (2020) Frequent neurologic manifestations and encephalopathy-associated morbidity in Covid-19 patients. Ann Clin Transl Neurol 7(11):2221-2230. https://doi.org/10.1002/acn3.51210 
5. Koh JS, De Silva DA, Quek AML et al (2020) Neurology of COVID-19 in Singapore. J Neurol Sci 418:117118. https://doi.org/10.1016/j.jns.2020.117118

6. Boldrini M, Canoll PD, Klein RS (2021) How COVID-19 affects the brain. JAMA Psychiatry 78(6):682-683. https://doi.org/10.1001/jamapsychiatry.2021.0500

7. Amanat M, Rezaei N, Roozbeh M, Shojaei M, Tafakhori A, Zoghi A, Darazam IA, Salehi M, Karimialavijeh E, Lima BS, Garakani A, Vaccaro A, Ramezani M (2021) Neurological manifestations as the predictors of severity and mortality in hospitalized individuals with COVID-19: a multicenter prospective clinical study. BMC Neurol 21(1):116. https://doi.org/10.1186/s12 883-021-02152-5

8. Liguori C, Pierantozzi M, Spanetta M, Sarmati L, Cesta N, lannetta M, Ora J, Mina GG, Puxeddu E, Balbi O, Pezzuto G, Magrini A, Rogliani P, Andreoni M, Mercuri NB (2020) Subjective neurological symptoms frequently occur in patients with SARS-CoV2 infection. Brain Behav Immun 88:11-16. https://doi. org/10.1016/j.bbi.2020.05.037

9. Romero-Sánchez CM, Díaz-Maroto I, Fernández-Díaz E, Sánchez-Larsen A, Layos-Romero A, García-García J, González E, Redondo-Peñas I, PeronaMoratalla AB, del Valle-Pérez JA, Gracia-Gil J, Rojas-Bartolomé L, Feria-Vilar I, Monteagudo M, Palao M, Palazón-García E, Alcahut-Rodríguez C, SopelanaGaray D, Moreno Y, Ahmad J, Segura T (2020) Neurologic manifestations in hospitalized patients with COVID-19: the ALBACOVID registry. Neurology 95(8):e1060-e1070. https://doi.org/10.1212/WNL.0000000000009937

10. Pinna P, Grewal P, Hall JP, Tavarez T, Dafer RM, Garg R, Osteraas ND, Pellack DR, Asthana A, Fegan K, Patel V, Conners JJ, John S, Silva ID (2020) Neurological manifestations and COVID-19: experiences from a tertiary care center at the frontline. J Neurol Sci 415:116969. https:/doi.org/10.1016/j.jns.2020.116969

11. Pinzon RT, Wijaya VO, Buana RB, al Jody A, Nunsio PN (2020) Neurologic characteristics in coronavirus disease 2019 (COVID-19): a systematic review and meta-analysis. Front Neurol 11:565. https://doi.org/10.3389/fneur.2020. 00565

12. Trigo J, García-Azorín D, Planchuelo-Gómez Á, Martínez-Pías E, Talavera B, Hernández-Pérez I, Valle-Peñacoba G, Simón-Campo P, de Lera M, ChavarríaMiranda A, López-Sanz C, Gutiérrez-Sánchez M, Martínez-Velasco E, Pedraza M, Sierra Á, Gómez-Vicente B, Arenillas JF, Guerrero ÁL (2020) Factors associated with the presence of headache in hospitalized COVID-19 patients and impact on prognosis: a retrospective cohort study. J Headache Pain 21(1):94. https://doi.org/10.1186/s10194-020-01165-8

13. Rocha-Filho PAS, Magalhães JE (2020) Headache associated with COVID-19: frequency, characteristics and association with anosmia and ageusia. Cephalalgia 40(13):1443-1451. https://doi.org/10.1177/0333102420966770

14. Membrilla JA, de Lorenzo Í, Sastre M, Díaz de Terán J (2020) Headache as a cardinal symptom of coronavirus disease 2019: a cross-sectional study. Headache 60(10):2176-2191. https://doi.org/10.1111/head.13967

15. Talavera B, García-Azorín D, Martínez-Pías E, Trigo J, Hernández-Pérez I, VallePeñacoba G, Simón-Campo P, de Lera M, Chavarría-Miranda A, López-Sanz C, Gutiérrez-Sánchez M, Martínez-Velasco E, Pedraza M, Sierra Á, GómezVicente B, Guerrero Á, Arenillas JF (2020) Anosmia is associated with lower in-hospital mortality in COVID-19. J Neurol Sci 419:117163. https://doi.org/1 0.1016/j.jns.2020.117163

16. Akbarialiabad H, Taghrir MH, Abdollahi A, Ghahramani N, Kumar M, Paydar S, Razani B, Mwangi J, Asadi-Pooya AA, Malekmakan L, Bastani B (2021) Long COVID, a comprehensive systematic scoping review. Infection 49(6):124. https://doi.org/10.1007/s15010-021-01666-x

17. de Mattos ACMT, de Souza JA, Moreira Filho PF et al (2017) ID-migraine ${ }^{\text {TM }}$ questionnaire and accurate diagnosis of migraine. Arq Neuropsiquiatr 75(7): 446-450. https://doi.org/10.1590/0004-282X20170069

18. López JT, García-Azorín D, Planchuelo-Gómez Á et al (2020) Phenotypic characterization of acute headache attributed to SARS-CoV-2: an ICHD-3 validation study on 106 hospitalized patients. Cephalalgia 40(13):1432-1442. https://doi.org/10.1177/0333102420965146

19. García-Azorín D, Sierra Á, Trigo J, Alberdi A, Blanco M, Calcerrada I, Cornejo A, Cubero M, Gil A, García-lglesias C, Lozano AG, Martínez Badillo C, Montilla C, Mora M, Núñez G, Paniagua M, Pérez C, Rojas M, Ruiz M, Sierra L, Hurtado ML, Guerrero Peral ÁL (2021) Frequency and phenotype of headache in covid-19: a study of 2194 patients. Sci Rep 11(1):14674. https://doi.org/10.1 038/s41598-021-94220-6

20. Fernández-de-las-Peñas C, Navarro-Santana M, Gómez-Mayordomo V, Cuadrado ML, García-Azorín D, Arendt-Nielsen L, Plaza-Manzano G (2021) Headache as an acute and post-COVID-19 symptom in COVID-19 survivors: a meta-analysis of the current literature. Eur J Neurol 28(11):3820-3825. https://doi.org/10.1111/ene.15040
21. Caronna E, Ballvé A, Llauradó A, Gallardo VJ, Ariton DM, Lallana S, López Maza S, Olivé Gadea M, Quibus L, Restrepo JL, Rodrigo-Gisbert M, Vilaseca A, Hernandez Gonzalez M, Martinez Gallo M, Alpuente A, Torres-Ferrus M, Pujol Borrell R, Alvarez-Sabin J, Pozo-Rosich P (2020) Headache: a striking prodromal and persistent symptom, predictive of COVID-19 clinical evolution. Cephalalgia 40(13):1410-1421. https://doi.org/10.1177/033310242 0965157

22. Hussein M, Fathy W, Eid RA, Abdel-Hamid HM, Yehia A, Sheemy MS, Ragaie C, Dahshan A, Rizk HI, laz N, Magdy R (2021) Relative frequency and risk factors of COVID-19 related headache in a sample of egyptian population: a hospital-based study. Pain Med (United States) 22(9):2092-2099. https://doi. org/10.1093/pm/pnab020

23. Poncet-Megemont L, Paris P, Tronchere A, Salazard JP, Pereira B, Dallel R, Aumeran C, Beytout J, Jacomet C, Laurichesse H, Lesens O, Mrozek N, Vidal M, Moisset X (2020) High prevalence of headaches during Covid-19 infection: a retrospective cohort study. Headache 60(10):2578-2582. https:// doi.org/10.1111/head.13923

24. García-Azorín D, Trigo J, Talavera B, Martínez-Pías E, Sierra Á, Porta-Etessam J, Arenillas JF, Guerrero ÁL (2020) Frequency and type of red flags in patients with Covid-19 and headache: a series of 104 hospitalized patients. Headache 60(8):1664-1672. https://doi.org/10.1111/head.13927

25. Gonzalez-Martinez A, Fanjul V, Ramos C, Serrano Ballesteros J, Bustamante M, Villa Martí A, Álvarez C, García del Álamo Y, Vivancos J, Gago-Veiga AB (2021) Headache during SARS-CoV-2 infection as an early symptom associated with a more benign course of disease: a case-control study. Eur J Neurol 28(10):3426-3436. https://doi.org/10.1111/ene.14718

26. Karadaş Ö, Öztürk B, Sonkaya AR, Taşdelen B, Özge A, Bolay H (2021) Latent class cluster analysis identified hidden headache phenotypes in COVID-19: impact of pulmonary infiltration and IL-6. Neurol Sci 42(5):1665-1673. https://doi.org/10.1007/s10072-020-04978-2

27. Planchuelo-Gómez Á, Trigo J, de Luis-García R, Guerrero ÁL, Porta-Etessam J, García-Azorín D (2020) Deep phenotyping of headache in hospitalized COVID-19 patients via principal component analysis. Front Neurol 11: 583870. https://doi.org/10.3389/fneur.2020.583870

28. Bolay H, Karadas Ö, Oztürk B, Sonkaya R, Tasdelen B, Bulut TDS, Gülbahar Ö, Özge A, Baykan B (2021) HMGB1, NLRP3, IL-6 and ACE2 levels are elevated in COVID-19 with headache: a window to the infection-related headache mechanism. J Headache Pain 22(1):94. https://doi.org/10.1186/s10194-02101306-7

29. Trigo J, García-Azorín D, Sierra-Mencía Á, Tamayo-Velasco Á, Martínez-Paz P, Tamayo E, Guerrero AL, Gonzalo-Benito H (2021) Cytokine and interleukin profile in patients with headache and COVID-19: a pilot, CASE-control, study on 104 patients. J Headache Pain 22(1):51. https://doi.org/10.1186/s10194021-01268-W

30. Magdy R, Hussein M, Ragaie C, Abdel-Hamid HM, Khallaf A, Rizk HI, Dahshan A (2020) Characteristics of headache attributed to COVID-19 infection and predictors of its frequency and intensity: a cross sectional study. Cephalalgia 40(13):1422-1431. https://doi.org/10.1177/0333102420965140

31. Vacchiano V, Riguzzi P, Volpi L, Tappatà M, Avoni P, Rizzo G, Guerra L, Zaccaroni S, Cortelli P, Michelucci R, Liguori R (2020) Early neurological manifestations of hospitalized COVID-19 patients. Neurol Sci 41(8):2029_ 2031. https://doi.org/10.1007/s10072-020-04525-z

32. Sampaio Rocha-Filho PA, Voss $L$ (2020) Persistent headache and persistent anosmia associated with COVID-19. Headache 60(8):1797-1799. https://doi. org/10.1111/head.13941

33. Al-Hashel JY, Abokalawa F, Alenzi M et al (2021) Coronavirus disease-19 and headache; impact on pre-existing and characteristics of de novo: a crosssectional study. J Headache Pain 22(1):97. https://doi.org/10.1186/s10194021-01314-7

34. Martelletti P, Bentivegna E, Luciani M, Spuntarelli V (2020) Headache as a prognostic factor for COVID-19. Time to re-evaluate. SN Compr Clin Med 2(12):2509-2510. https://doi.org/10.1007/s42399-020-00657-7

35. Martelletti P, Bentivegna E, Spuntarelli V, Luciani M (2021) Long-COVID headache. SN Compr Clin Med 3(8):1704-1706. https://doi.org/10.1007/s423 99-021-00964-7

36. Tong JY, Wong A, Zhu D, Fastenberg JH, Tham T (2020) The prevalence of olfactory and gustatory dysfunction in COVID-19 patients: a systematic review and Meta-analysis. Otolaryngol - Head Neck Surg (United States) 163(1):3-11. https://doi.org/10.1177/0194599820926473

37. Saniasiaya J, Islam MA, Abdullah B (2021) Prevalence of olfactory dysfunction in coronavirus disease 2019 (COVID-19): a Meta-analysis of 
27,492 patients. Laryngoscope 131(4):865-878. https://doi.org/10.1002/lary.2 9286

38. Siddiqi HK, Mehra MR (2020) COVID-19 illness in native and immunosuppressed states: a clinical-therapeutic staging proposal. J Hear Lung Transplant 39(5):405-407. https://doi.org/10.1016/j.healun.2020.03.012

39. Lippi G, Sanchis-Gomar F, Henry BM (2020) COVID-19: unravelling the clinical progression of nature's virtually perfect biological weapon. Ann Transl Med 8:693-693. https://doi.org/10.21037/atm-20-3989

40. Barrantes FJ (2021) The unfolding palette of COVID-19 multisystemic syndrome and its neurological manifestations. Brain Behav Immun-Heal 14: 100251. https://doi.org/10.1016/.jbbih.2021.100251

41. Lechien JR, Chiesa-Estomba CM, De Siati DR et al (2020) Olfactory and gustatory dysfunctions as a clinical presentation of mild-to-moderate forms of the coronavirus disease (COVID-19): a multicenter European study. Eur Arch Oto-Rhino-Laryngol 277(8):2251-2261. https://doi.org/10.1007/s00405020-05965-1

42. Porta-Etessam J, Matías-Guiu JA, González-García N, Gómez Iglesias P, Santos-Bueso E, Arriola-Villalobos P, García-Azorín D, Matías-Guiu J (2020) Spectrum of headaches associated with SARS-CoV-2 infection: study of healthcare professionals. Headache 60(8):1697-1704. https://doi.org/10.1111/ head. 13902

43. Aragão MFW, de Carvalho Leal M, Queiroga Cartaxo Filho O et al (2020) Anosmia in COVID-19 associated with injury to the olfactory bulbs evident on MRI. Am J Neuroradiol 41:1703-1706. https://doi.org/10.3174/ajnr.a6675

44. Helms J, Kremer S, Merdji H, Clere-Jehl R, Schenck M, Kummerlen C, Collange O, Boulay C, Fafi-Kremer S, Ohana M, Anheim M, Meziani F (2020) Neurologic features in severe SARS-CoV-2 infection. N Engl J Med 382(23): 2268-2270. https://doi.org/10.1056/nejmc2008597

45. Rebora P, Rozzini R, Bianchetti A, Blangiardo P, Marchegiani A, Piazzoli A, Mazzeo F, Cesaroni G, Chizzoli A, Guerini F, Bonfanti P, Morandi A, Faraci B, Gentile S, Bna C, Savelli G, Citerio G, Valsecchi MG, Mazzola P, Bellelli G, for the CoViD-19 Lombardia Team (2021) Delirium in patients with SARS-CoV-2 infection: a multicenter study. J Am Geriatr Soc 69(2):293-299. https://doi. org/10.1111/jgs. 16969

\section{Publisher's Note}

Springer Nature remains neutral with regard to jurisdictional claims in published maps and institutional affiliations.

Ready to submit your research? Choose BMC and benefit from:

- fast, convenient online submission

- thorough peer review by experienced researchers in your field

- rapid publication on acceptance

- support for research data, including large and complex data types

- gold Open Access which fosters wider collaboration and increased citations

- maximum visibility for your research: over $100 \mathrm{M}$ website views per year

At $\mathrm{BMC}$, research is always in progress.

Learn more biomedcentral.com/submissions 